\title{
Symposium Lead Essay_Conflict of Interest: Opening Up New Territories
}

\author{
Miriam Wiersma • Wendy Lipworth • \\ Paul Komesaroff • Ian Kerridge
}

Published online: 14 July 2020

(C) Journal of Bioethical Inquiry Pty Ltd. 2020

Over the last few decades, awareness of the importance of managing conflicts of interest among health-related policymaking, professional, research, and clinical institutions has greatly increased. The visibility of the issue - and the widespread use of the expression "conflict of interests"-may give the impression that the underlying concepts have been clearly defined and that there is widespread consensus about processes and practices. Sadly, this is not the case. In reality, conflicts of interests are far more complex than is commonly appreci-

M. Wiersma $(\bowtie) \cdot$ W. Lipworth $\cdot$ I. Kerridge

The University of Sydney, Sydney Health Ethics, Level 1, Medical Foundation Building, K25, Sydney, NSW 2006, Australia

e-mail: miriam.wiersma@sydney.edu.au

e-mail: mwie6377@uni.sydney.edu.au

W. Lipworth

e-mail: wendy.lipworth@sydney.edu.au

I. Kerridge

e-mail: ian.kerridge@sydney.edu.au

P. Komesaroff

Centre for Ethics in Medicine and Society, Alfred Hospital, Monash University, Commercial Road, Prahran, Victoria, Australia

e-mail: paul.komesaroff@monash.edu

\section{Kerridge}

Haematology Department, Royal North Shore Hospital, Reserve Rd, St Leonards, NSW 2065, Australia ated and, because of their importance, require ongoing detailed, rigorous analysis and debate.

Early analyses of conflict of interest (COI) focused on the conceptualization of COI, how to determine when COIs are "unethical," and how they should be managed (Thompson 1993; Goldrick et al. 1994; Marshall 1992; Levinsky 2002; Pellegrino 1992; Horrobin 1999). Evidence has now clearly revealed the adverse impact that financial COIs may have on the integrity of research, development of clinical guidelines, clinical care, and continuing medical education (CME) (Lundh et al. 2017). Attention has been paid in particular to the relationships between clinicians, researchers, and the pharmaceutical and medical device industries; and management strategies, such as the disclosure of financial ties or recusal where necessary, have been implemented across multiple biomedical domains, including in publication, the development of clinical guidelines, and in some areas of clinical practice. The weakness of "disclosure" alone as a management strategy has been recognized, and the necessity of the development of sophisticated management strategies for financial COIs remains an ongoing focus of academic inquiry.

The significance of non-financial COIs in contrast, continues to be debated, with varying views as to whether they should be regarded as a type of "conflict of interest" and whether they are simply too widespread and diverse to be managed effectively (Bero 2017; Wiersma, Kerridge, and Lipworth 2018; Wiersma 
et al. 2018). Confusion also continues about the nature of "financial" COIs, which are the focus of much of the extant literature. It is sometimes assumed that financial COIs are simply conflicts that are quantifiable in numerical terms, whereas in fact they are COIs that happen to have a financial component. The "interest" referred to here is not the amount of money but rather the moral force it carries for a particular individual; in other words, a "financial conflict of interest" is an influence that is linked to money (Komesaroff et al. 2019).

Unfortunately, debate about conflicts of interest has largely stagnated in recent years-with the concept remaining under-theorized, and often associated with rigid, repetitive, self-contradictory, and, at times, polemical formulations. Our purpose in convening this symposium has been to introduce new ideas into this debate from a wide range of scholars with diverse backgrounds (including law, bioethics, sociology, and philosophy). Together, these articles trace COIs across different countries-from Australia to China and North America; they explore different conceptualizations of interests and COI; and they put forward new arguments for and against addressing non-financial COIs and investigate the impact of COIs on health and biomedicine (Mayes 2020; Nie et al. 2020; Marks 2020; Giubilini and Savulescu 2020; Goldberg 2020; Wiersma et al. 2020).

Jonathan Marks and Jing Bao's articles focus on financial COIs-with both authors calling for greater attention to institutional COIs, and the socio-political and cultural contexts in which they arise (Marks 2020; Nie et al. 2020). Marks' article explores the influence of pharmaceutical companies on the formation and exacerbation of the opioid crisis in North America. Not unlike the strategies deployed by the tobacco and sugar industries, he describes the extensive web of influence-involving payments to physicians, multi-million dollar donations to universities and academic medical institutions, funding of patient advocacy groups, payments to political campaigns and public health initiatives - woven by pharmaceutical companies in order to downplay the risk of harm from opioids and to maximize company profits (Marks 2020).

Marks calls for greater attention to institutional COIs and to the broader societal and cultural practices that encourage partnerships between academic institutions, public health agencies, non-government organizations, and the pharmaceutical industry. He considers publicprivate partnerships with pharmaceutical companies to be inherently ethically problematic, arguing that they create health risks, threaten public trust, and compromise the institutional integrity of public health organizations. Consequently, Marks argues that we must rethink the public-private partnerships that are increasingly the norm in public health, and move away from collaboration to a new norm of separation (Marks 2020).

In their article, Nie and colleagues use the case of $\mathrm{He}$ Jiankui- the infamous genetic scientist who produced so called "gene edited babies"- to explore institutional conflicts of interest in scientific research and healthcare in China (Nie et al. 2020). While a Chinese court has focused on his personal wrongdoing and recently sentenced him to jail "for illegal medical practices," Nie and colleagues note the lack of attention that has been given to COIs, and in particular, institutional COIs in China, and critique the broader socio-political and cultural context in which He's "experiment" took place.

The analysis by Nie et al. sheds light on multiple factors - including the importance attributed to the acceleration of biomedical research at a national level; government incentives to researchers for "groundbreaking" research discoveries; state policies pushing the commercialization of scientific research; and a lack of clear guidelines and policies pertaining to the disclosure of COIs - that created the context in which He's crimes occurred. This, they argue, points to the necessity of institutional reform-including the development of national legislation, policies, and guidelines on $\mathrm{COI}$ (Nie et al. 2020).

Wiersma et al. (2020) present the results of a study exploring Australian medical professionals' experiences and attitudes towards conflicts of interests. These professionals identified the pursuit of status and respect and the avoidance of stigma as important non-financial interests for medical professionals, that may come into conflict with prioritizing patient care and the integrity of the research process. While this was a small qualitative study, it reveals that medical professionals are willing to acknowledge and are capable of identifying nonfinancial interests and conflicts of interestparticularly those that they perceive to be ethically problematic (Wiersma et al. 2020).

Goldberg (2020) and Giubilini and Savulescu (2020) also focus on non-financial COIs. Goldberg argues that financial COIs are of a higher ethical priority than what 
he calls "intellectual" COIs (defined as "academic activities that create the potential for a specific point of view that could unduly affect an individual's judgement about a specific recommendation") (Akl et al. 2014; Goldberg 2020). Goldberg does not question the existence of intellectual COIs or deny that they may motivate bias; rather, he questions whether the source of motivated bias from an intellectual COI is as significant as that from a financial COI. Ultimately, he concludes that financial COIs are of a greater normative priority than intellectual COIs because financial COIs dramatically impact upon trust in a social role and are eliminable, whereas intellectual COIs are not (Goldberg 2020).

In sharp contrast, Giubilini and Savulescu reject the notion that financial COIs are more ethically problematic than non-financial COIs and use a number of hypothetical case scenarios to demonstrate how non-financial COIs may adversely influence health practitioners' decision-making (Giubilini and Savulescu 2020). They focus on clinicians' moral and religious beliefs as a type of non-financial interest that may at times generate a COI. Central to their argument is the claim that conscientious objection - a clinician's refusal to take part in a legitimate medical intervention because it conflicts with their religious or moral beliefs - gives inappropriate credence to what should be considered an impermissible non-financial COI, because it allows clinicians' personal moral or religious values to be prioritized above clinical judgement. The authors recommend adopting strategies used to manage financial COIs for the management of religious beliefs (Giubilini and Savulescu 2020).

Mayes' critique of the very concept of conflict of interest draws attention to the potentially erroneous assumptions underpinning the popular definition of $\mathrm{COI}-$ that is, COI as a "set of conditions in which professional judgement concerning a primary interest ... tends to be unduly influenced by a secondary interest" (Thompson 1993, 1; Lo and Field 2009). Mayes argues that, in order to have utility, there needs to be a clear hierarchy of interests upon which definitions of conflicts of interest can draw. The commercialization of healthcare calls into question whether such hierarchies exist which, in turn, calls into question the very utility of the concept of conflict of interest (Mayes 2020). He maintains that COI is a specific tool that is only applicable to a small set of medico-legal issues and calls us to pay careful attention to the social and political environment that sustains the values of the market within medicine (Mayes 2020).
While the articles in this symposium diverge on key issues, they all problematize conflict of interest in novel ways and move beyond standard tropes such as calls for greater disclosure of interests and punishment of those who have them. We hope that these articles will challenge attempts to simplify conflict of interest and draw clear lines between, for example, financial and non-financial interests. We also hope that this symposium will be used as the starting points of new threads of more nuanced debate.

\section{References}

Akl, E.A., P. El-Hachem, H. Abou-Haidar, et al. 2014. Considering intellectual, in addition to financial, conflicts of interest proved important in a clinical practice guideline: a descriptive study. Journal of Clinical Epidemiology 67(11): 1222-1228.

Bero, L. 2017. Addressing bias and conflict of interest among biomedical researchers. JAMA 317(17): 1723-1724.

Goldberg, D. 2020. Financial conflicts of interest are of higher ethical priority than "intellectual" conflicts of interest. Journal of Bioethical Inquiry 17(2): https://doi.org/10.1007 /s11673-020-09989-4.

Goldrick, B., E. Larson, and D. Lyons. 1994. Conflict of interest in academia. Journal of Nursing Scholarship 27(1): 65-69.

Giubilini, A., and J. Savulescu. 2020. Beyond money: Conscientious objection in medicine as a conflict of interest. Journal of Bioethical Inquiry 17(2): https://doi.org/10.1007 /s11673-020-09976-9.

Horrobin, D. 1999. Non-financial conflicts of interest are more serious than financial conflicts. The BMJ 318(7181): 466.

Komesaroff, P.A., I. Kerridge, and W. Lipworth. 2019. Conflicts of interest: New thinking, new processes. Internal Medicine Journal 49(5): 574-577.

Levinsky, N.G. 2002. Nonfinancial conflicts of interest in research. New England Journal of Medicine 347(10): 759-761.

Lo, B., and M. Field. 2009. Conflict of interest in medical research, education, and practice Washington, D.C: National Academies Press.

Lundh, A., J. Lexchin, B. Mintzes, et al. 2017. Industry sponsorship and research outcome. Cochrane Database of Systematic Reviews: MR000033.

Marks, J. 2020. Lessons from corporate influence in the opioid epidemic: Toward a norm of separation. Journal of Bioethical Inquiry 17(2): https://doi.org/10.1007/s11673020-09982-x.

Marshall, E. 1992. When does intellectual passion become conflict of interest? Science 257 (5070): 620-625.

Mayes, C. 2020. After conflicts of interest: From procedural shortcut to ethico-political debate. Journal of Bioethical Inquiry 17(2): https://doi.org/10.1007/s11673-020-09971-0.

Nie, J., G. Xie, H. Chen, and Y. Cong. 2020. Conflicts of interest in scientific research in China: A socio-ethical analysis of $\mathrm{He}$ Jiankui's human gene-editing experiment. Journal of Bioethical Inquiry 17(2): https://doi.org/10.1007/s11673020-09978-7. 
Pellegrino, E. 1992. Beneficence, scientific autonomy and selfinterest: Ethical dilemmas in clinical research. Cambridge Quarterly of Healthcare Ethics 1(4): 361-369.

Thompson, D.F. 1993. Understanding financial conflicts of interest. New England Journal of Medicine 329(8): 573-576.

Wiersma, M., I. Kerridge, and W. Lipworth. 2018. Dangers of neglecting non-financial conflicts of interest in health and medicine. Journal of Medical Ethics 44(5): 319-322.
2020. Status, respect and stigma: A qualitative study of non-financial interests in medicine. Journal of Bioethical Inquiry 17(2).

Wiersma, M., I. Kerridge, W. Lipworth, and M. Rodwin. 2018. Should we manage non-financial interests? BMJ 361: https://doi.org/10.1136/bmj.k1240

Publisher's note Springer Nature remains neutral with regard to jurisdictional claims in published maps and institutional affiliations. 